\title{
Synoptic Study of the Vertical Distribution of the Radio Refractive Index ${ }^{1}$
}

\author{
B. R. Bean, L. P. Riggs, and J. D. Horn
}

(March 12, 1959)

\begin{abstract}
An analysis of the vertical structure of an intense outbreak of continental polar air is presented in terms of the radio refractive index of the atmosphere. Employed for the first time is a reduced index analogous to potential temperature. The reduced value more clearly shows the refractive index structure than the classical methods used heretofore. This new unit is a measure of both atmospheric density and humidity and shows, on a single cross section, the airmass structure and the dynamic mixing of air around the frontal interface.
\end{abstract}

\section{Introduction}

The problem of determining the vertical and horizontal distribution of the index of refraction of the troposphere for radiofrequencies has engaged the attention of radio meteorologists for the past decade $[1,2,3,4]^{2}$. Such information is vital to procedures and techniques for forecasting the occurrence of radio refractive-index profiles. The surface value and the gradient of the refractive index are important factors in the prediction of monthly median values of field strength over communication links utilizing frequencies from 50 to $50,000 \mathrm{Mc}[5,6,7]$.

For convenience, the refractive index is given in terms of its scaled up value, $N$, commonly called the refractivity:

$$
N=(n-1) 10^{6} .
$$

$N$ may be determined [8] from standard weather observations by

$$
N=(n-1) 10^{6}=\frac{77.6}{I^{\prime}}\left[\frac{P+4810 e_{s} R H}{T}\right],
$$

where

$n=$ index of refraction of the atmosphere,

$T=$ temperature in degrees Kelvin,

$P=$ station pressure in millibars,

$e_{s}=$ saturation vapor pressure, and

$R H=$ relative humidity, in percent.

\section{Background}

A worldwide survey of $N$ elimatology [9] indicates that the refractive index varies widely over the surface of the earth. If we take the modern view that climatology is a synthesis of synoptic events then we may conclude that the frequency of occurrence of airmass types and frontal passages play an important

1 This work was supported in part by Task 31 of the Navy Weather Research Facility, Naval A ir Station, Norfolk, Va.

2 Figures in brackets indicate the literature references at the end of th jipaper. role in determining the refractive-index climate at any location.

Recent studies have shown that the $N$ profile at a given location varies with synoptic pattern [10] and that, if one reduces $N$ to sea level, the refractive index is a sensitive indicator of large-scale weather systems [11] when considered on a daily weather map basis. The present study extends the work of reference [11] by considering if the air mass properties associated with a typical wintertime outbreak of polar air are reflected in the refractive-index structure. A storm sequence with strong contrasts of airmass properties was chosen for study under the premise that if the refractive index failed to indicate the differences in airmass properties in this case then there is little hope of its being effective in situations with less marked temperature and humidity contrasts.

Before proceeding one might inquire if the particular case chosen for study was a representative one or not. As a guide in this regard, idealized models (figs. 1 and 2) of cold and warm fronts were con-

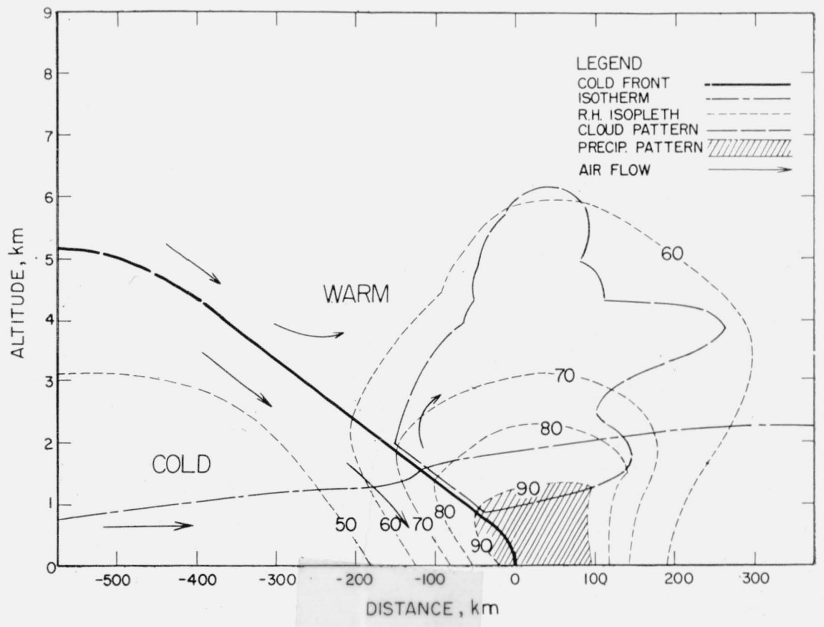

Figure 1. An idealized cold front with associated temperature and humility patterns. 


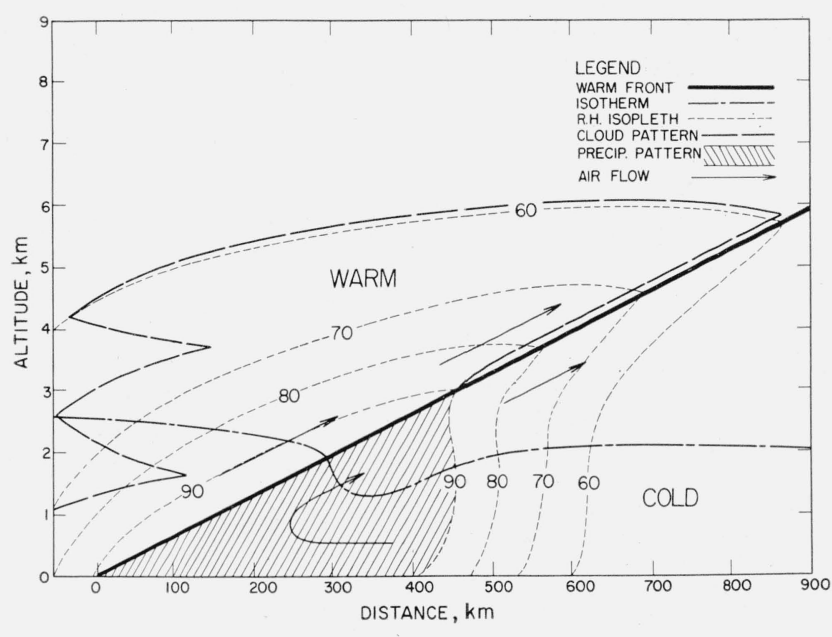

Figure 2. An idealized warm front with associated temperature and humidity patterns.

structed from generally accepted concepts of the polar front $[12,13,14]$. From these models, idealized $N$ fields were constructed. This idealized $N$ structure (figs. 3 and 4 ) is in agreement with that derived from a classic storm reported by Byers [13]. The most prominent feature of this idealized situation is the laminar structure of the $N$ field reflecting a uniform decrease of $N$ with height so pronounced that it masks the airmass contrasts about the front which are the main concern of this study. In the sections that follow we shall be concerned with the removal of the normal $N$ decrease with height in order to more clearly see the $N$ changes associated with the storm under study.

\section{Height Dependence of $\mathrm{N}$}

It has long been recognized that the pressure term in $N$ results in a steady decrease of $N$ with increasing height. Early attempts to compensate for this $N$ decrease used the constant gradient of the effective earth's radius theory, $1 / 4 a$, where $a$ is the radius of the earth. As an illustration, the strong elevated layer

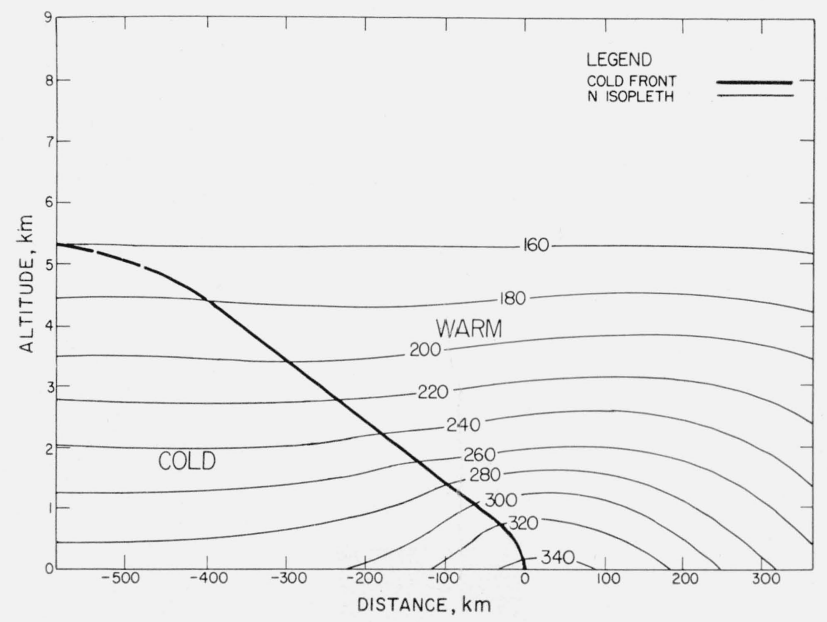

Figure 3. The $\mathrm{N}$ field of an idealized cold front.

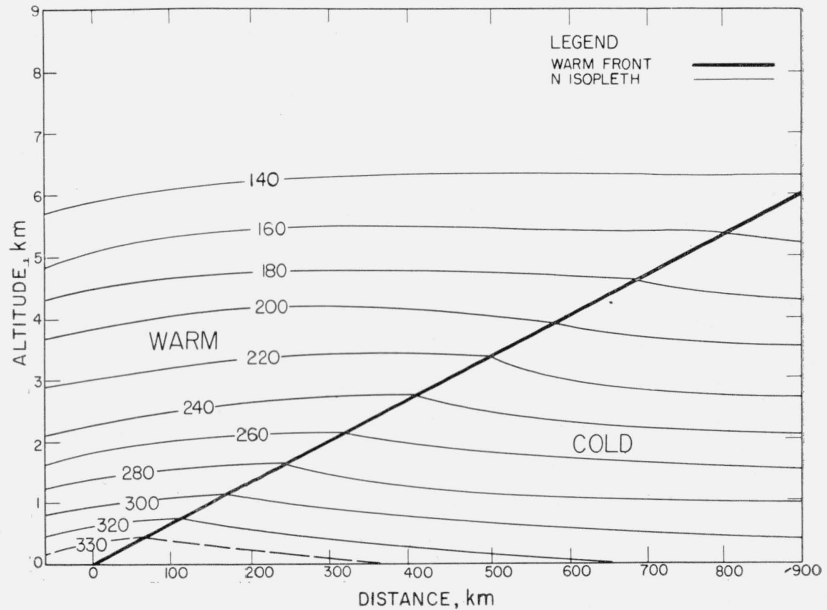

Figure 4. The $\mathrm{N}$ field of an idealized warm front.

found during the summer in Southern California was studied in terms of a linearly corrected expression, $B$, given by

$$
B=N(h)+39.2 h
$$

where $N(h)$ is the value of $N$ at any height, $h$, in kilometers [15]. Recent studies of the average $N$ structure of the atmosphere show that $N$ tends to be an exponential function of height rather than the linear function assumed by the effective earth's radius theory, with the result that the $B$ unit approach overcorrects when $h$ is greater than about $1 \mathrm{~km}$. This is illustrated by figures 5 and 6 where the $N$ data of figures 3 and 4 are replotted in terms of $B$ units. Note that this over correction produces an $N$ field that tends to increase with height from 310 at the surface to 360 at $5 \mathrm{~km}$. If, however, one presents these data in terms of an exponential function, $A$, of the form

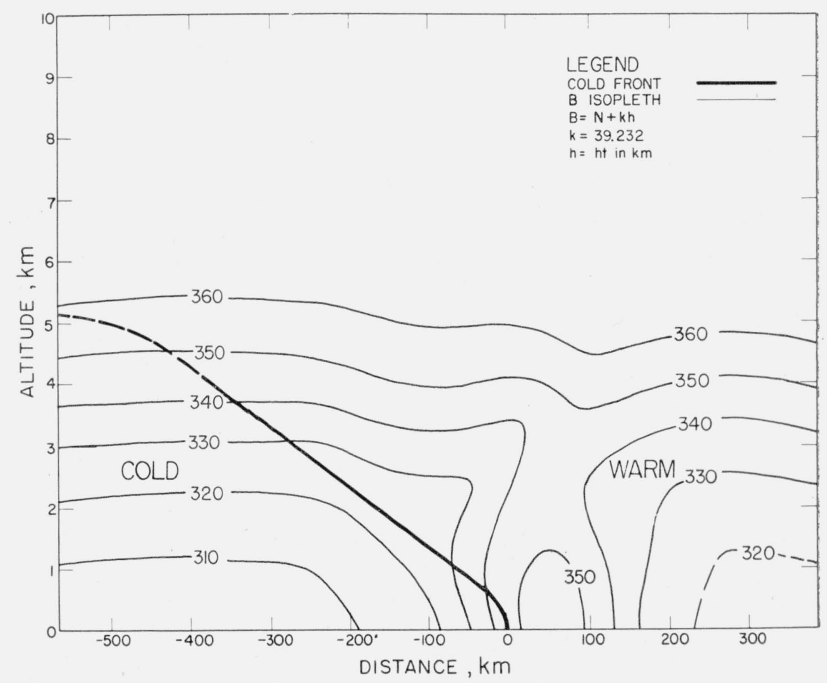

Figure 5. The refractive index structure in B units for an idealized cold front. 


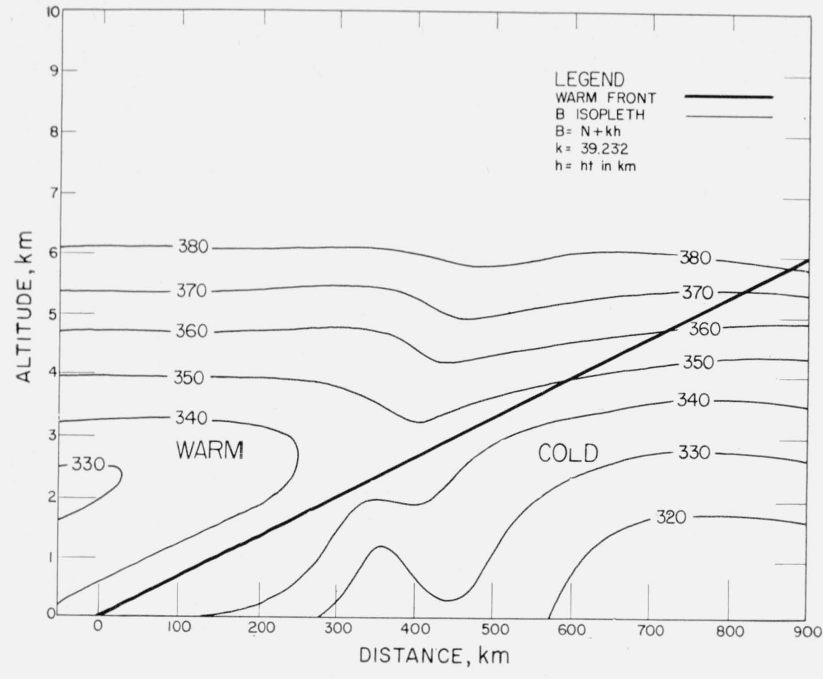

Figure 6. The refractive index structure in $\mathrm{B}$ units for an idealized warm front.

$$
A=N(h)+313[1-\exp \{-0.144 h\}],
$$

as in figures 7 and 8 , then it is seen that the range of $N$ values is now reduced to about $25 N$ units. The exponential decay coefficient of 0.144 was determined to correspond with the average station value of $N$, 313 for the United States [16]. It is significant, however, that the use of $A$ units produces a pattern similar to the airmass differences associated with the frontal zone. Note, in the warm front case (fig. 8), that the $A$ values increase with height until they reach a maximum associated with the upgliding warm moist air overriding the frontal surface. The region of maximum precipitation 400 to $500 \mathrm{~km}$ in advance of the front is shown as an area of high surface $N$. In the cold-front case (fig. 7) the classic push of warm air aloft by the encroaching cold air is

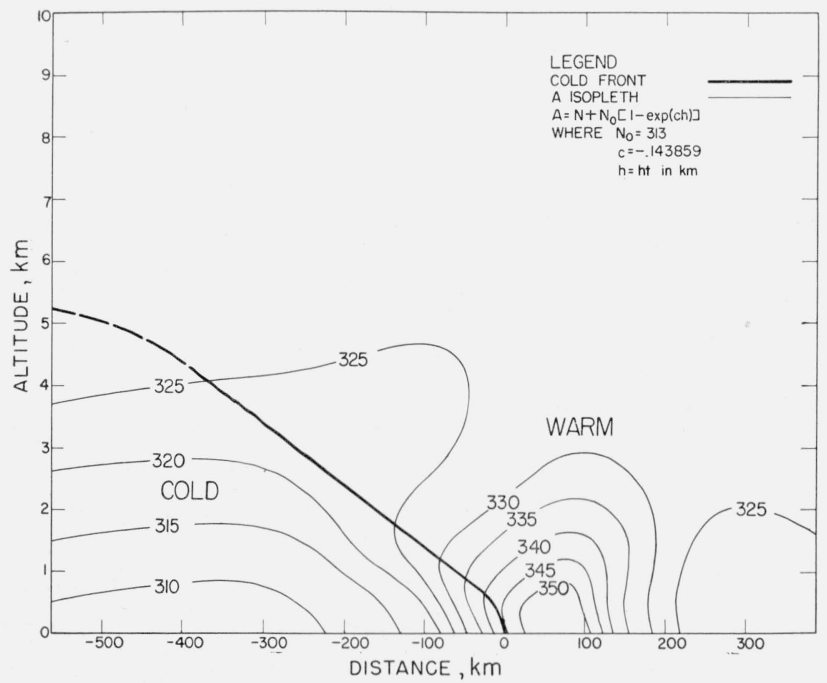

Figure 7. The refractive index pattern in A units for an idealized cold front. evidenced by the "dome" of high $A$ values just before the front. Stratification in the cold air due to subsidence-inversion effects, although impossible to detect in the $N$ charts, is clearly seen by the use of the $A$ charts.

$A$ units were used in all subsequent analysis in order to throw the frontal discontinuities and airmass differences into sharp relief. To facilitate this transformation, a Potential Refractivity Chart (fig. 9)

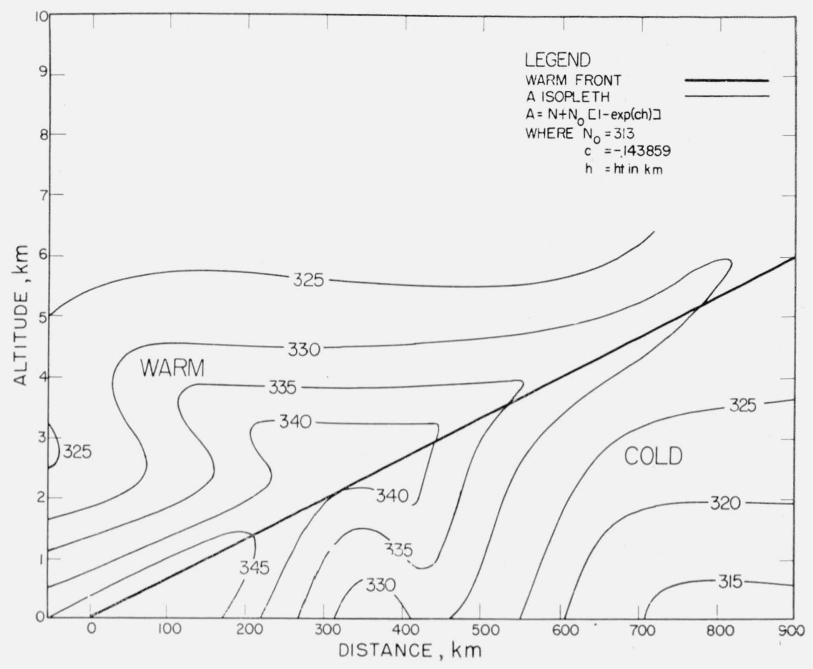

Figure 8. The refractive index pattern in A units for an idealized warm front.

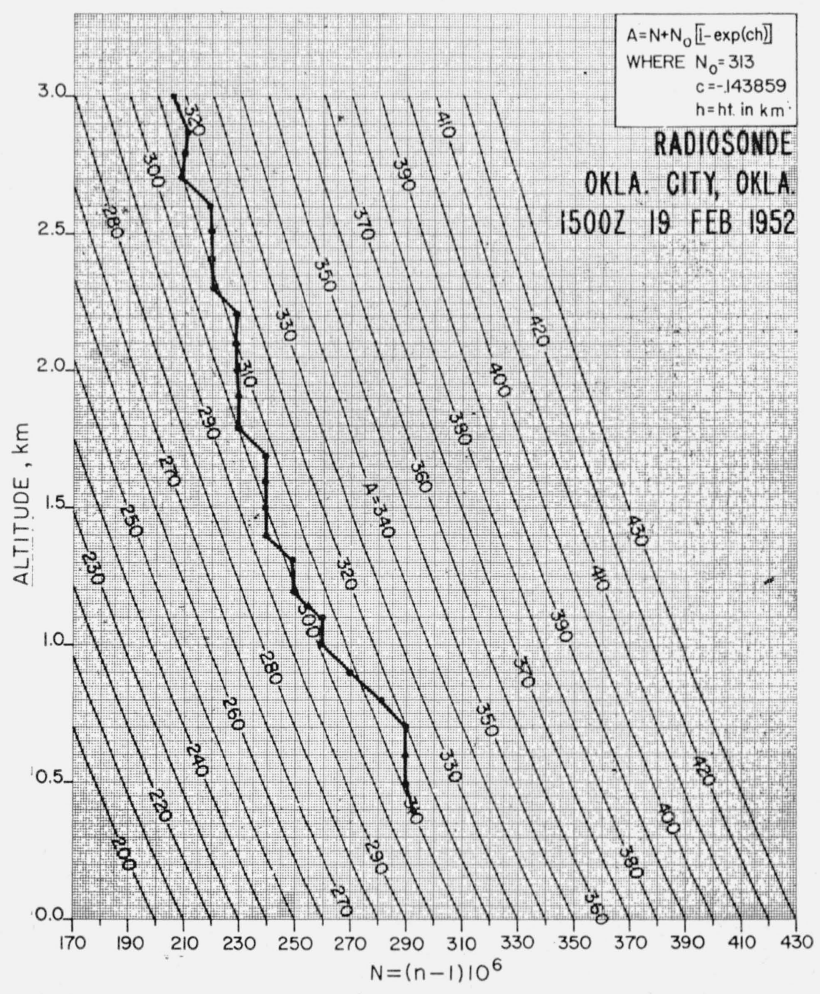

Figure 9. Potential refractivity chart with radiosonde data shown in A units.

$A$ is obtained by plotting $N$ versus altitude and interpolating from the lines of constant potential refractivity. 
was prepared for rapid conversion from $N$ units to $A$ units. This simplification eliminates the necess ty of using exponential tables for each individual alculation of $A$ and thus lends considerable ease to the preparation of charts of the new parameter.

\section{Storm of February 18 to 21, 1952}

A large-scale outbreak of polar continental air which took place over the United States between the 18th and 21st of February 1952, was analyzed in terms of $A$ units. Charts showing the structure of this outbreak of polar continental air have been prepared from the radiosonde measurements from stations located along a line normal to the front running from Glasgow, Mont. to Lake Charles, La. (fig. 10). The height distributions of unit contours along this cross-section line were obtained at 12-hr intervals during the 4-day period. Examples are given (figs. 11 to 13) to represent the early, mature, and late stages of the outbreak. At the outset of the period of observation, the $A$ unit gradient was quite flat around the polar front. By $1500 \mathrm{Z}$ on the 18th of February (fig. 11) the polar front was located midway between Glasgow and Dodge City. The contrast of the southward push of polar air and the northerly advection of tropical maritime air from the Gulf of Mexico into the developing warm sector of the polar-front wave is evidenced by the relatively large gradients in the neighborhood of Dodge City. The core of tropical maritime air has evidently not progressed far enough northward to displace the warm but dry air that had been over the great plains prior to the outbreak with the result that a region of low $A$ values is found between the front and the tropical maritime air. Twenty-four hours later (fig. 12) the core of tropical maritime air has become more extensive and now reaches to $3 \mathrm{~km}$. A second cold front was reported on the daily weather map and the area of low $A$ values is now confined between

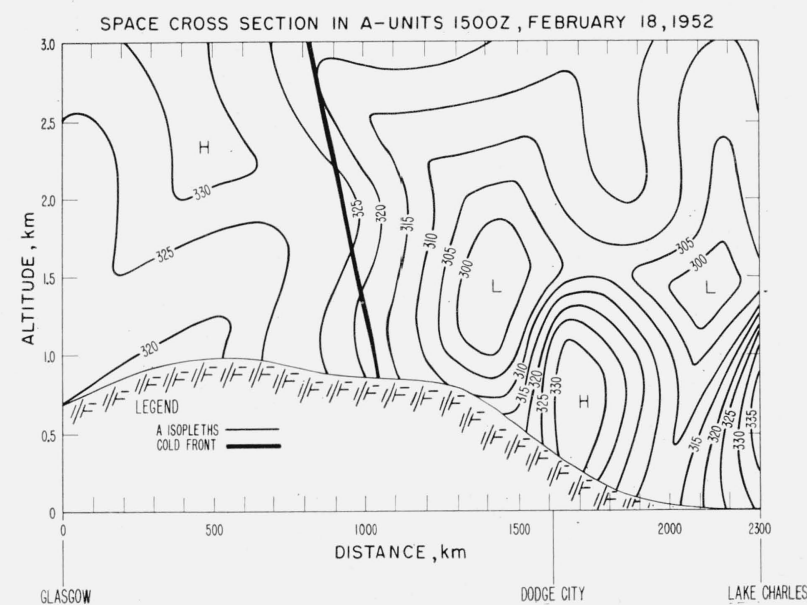

Figure 11. Early stage of the storm sequence.

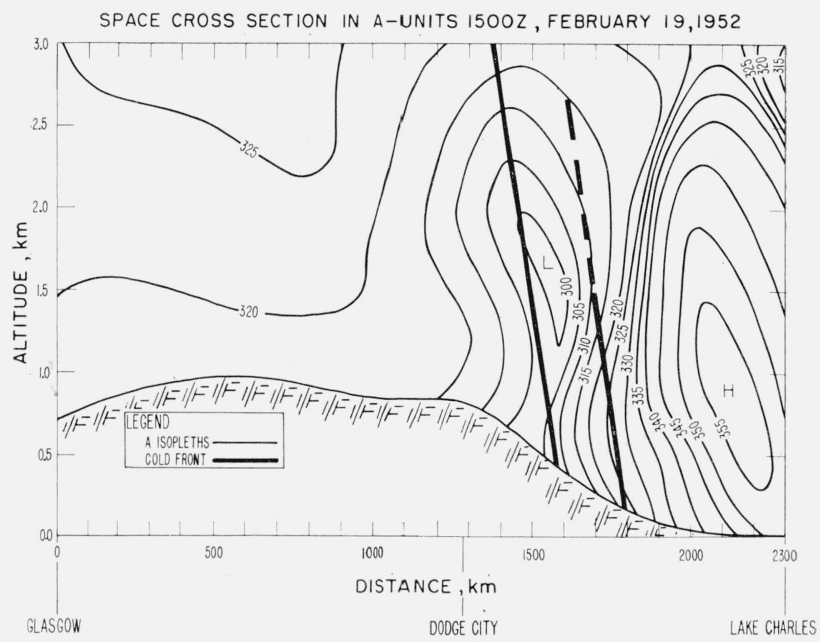

Figure 12. Mature stage of the storm sequence.

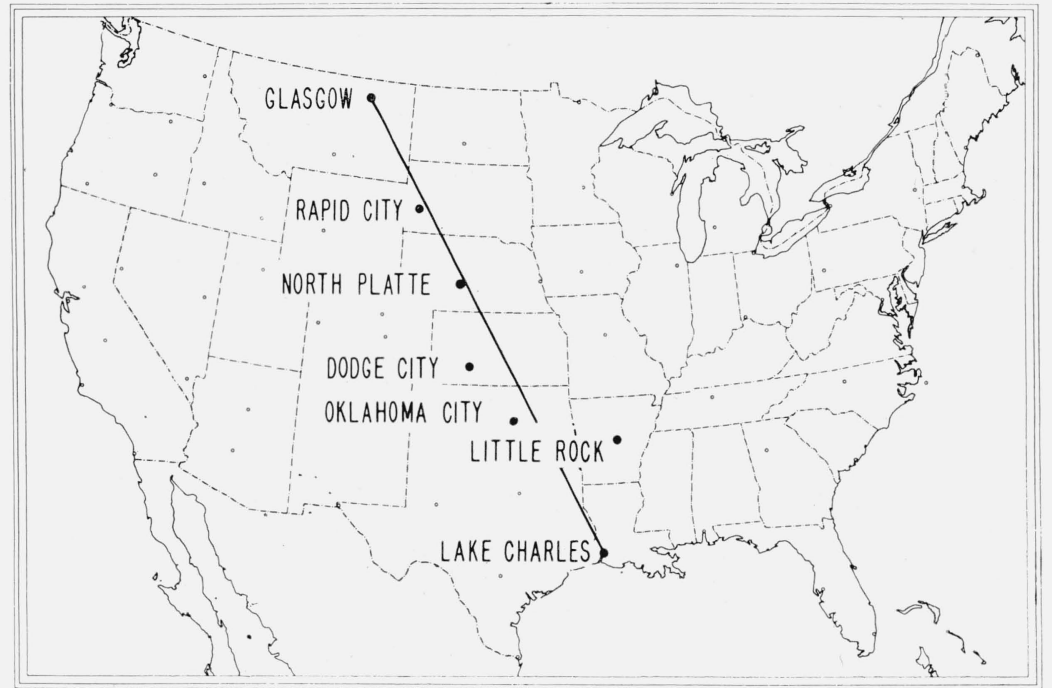

FIgURE 10. Location chart of the stations furnishing radiosonde data for this study. 


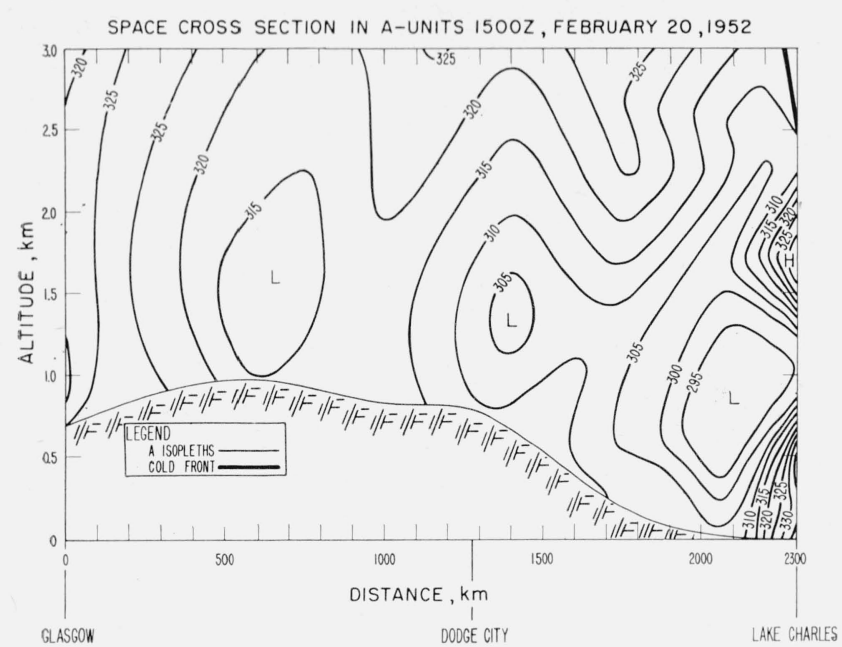

Figure 13. Late stage of the storm sequence.

it and the main cold front. Finally, by the morning of February 20 (fig. 13), the front has passed to the south of Lake Charles and the polar air just behind the front is characterized by relatively low $A$ values.

The use of space cross sections does not always yield measurements at the most desirable points along a frontal zone. Another method of arriving at the probable refractive-index structure about the frontal interface is to present each successive radiosonde observation at a single location in terms of the distance between the front and the station. Thus, as the frontal system advances and passes over the station, one obtains a different perspective of the space cross section. This presentation is referred to as an epoch chart since the observations are normalized with respect to the frontal passage. Such a presentation is given on figures 14 and 15 . Figure 14 represents a typical continental station located in the polar continental air throughout the occurrence of

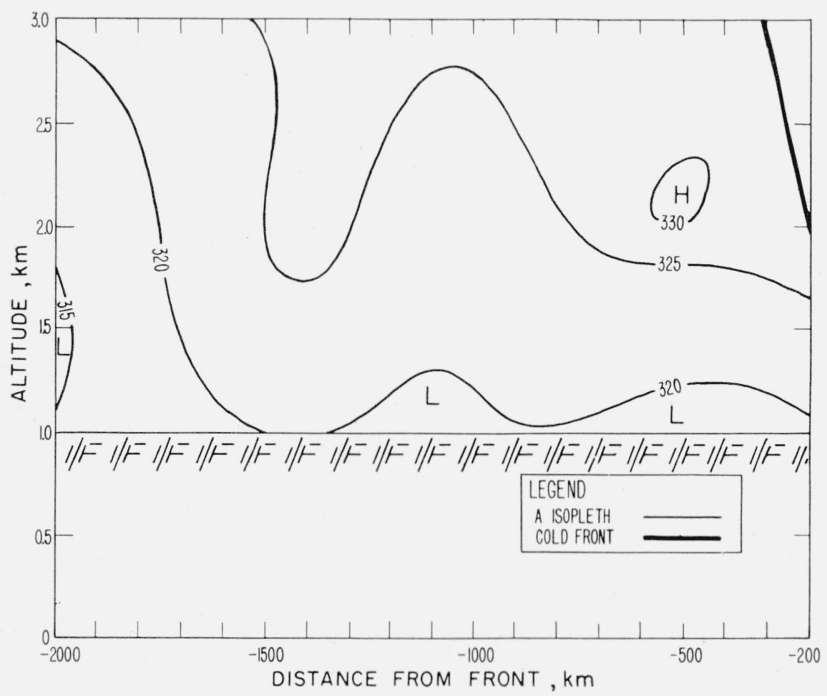

Figure 14. The A unit pattern for Rapid City, S. Dak., expressed as a function of the distance from the front.

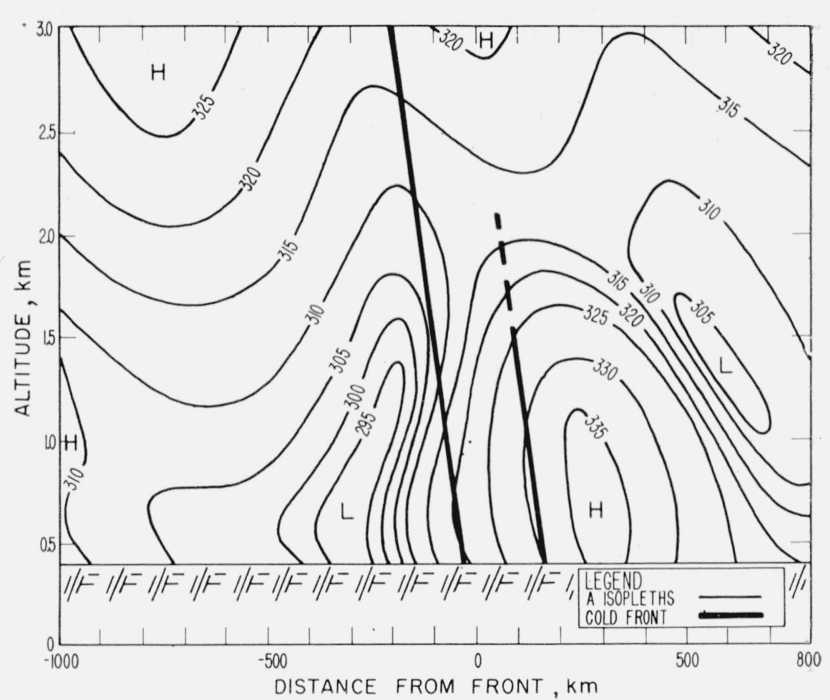

Figure 15. The A unit pattern for Oklahoma City, Okla., expressed as a function of the distance from the front.

the storm. The essential feature here is the absence of detail of $A$ structure due to the presence of a uniform airmass over this station. Compare this with the epoch chart for Oklahoma City (fig. 15) where the structure of the idealized model is clearly reflected by the prefrontal $A$ unit high, strong gradient across the frontal zone, and the $A$ unit low behind the front. This rather fortuitous agreement is felt to be due to the strategic location of Oklahoma City with respect to the motion of the contrasting airmasses about the polar front. That is, this epoch chart represents a point of confluence of virtually unmodified polar continental and tropical maritime air.

\section{Conclusions}

The major conclusion of the present study is that an exponential correction to the refractive-index height distribution allows airmass properties to be more clearly seen than is allowed by previous techniques.

By the use of this exponential correction one may construct an idealized refractive-index field about a frontal transition zone that clearly shows the temperature and humidity contrasts of the different airmasses.

Further, when this technique is applied to the analysis of an actual storm, it does indeed highlight airmass differences.

\section{References}

[1] P. A. Sheppard, The structure and refractive index of the atmosphere, Rept. Conf. Meteorol. Factors Radio Wave Propagation (1946).

[2] N. G. Gerson, Variations in the index of refraction of the atmosphere, Geofisica Pura E Applicata 13, 88 (1948).

[3] Andree Perlat, Meteorology and radioelectricity, L'Onde Elec. 28, 44 (1948).

[4] D. R. Hay, Airmass refractivity in central Canada, Can. J. Phys. 43, 12 (1958). 
[5] K. A. Norton, P. L. Rice, and L. E. Vogler, The use of angular distance in estimating transmission loss and fading range for propagation through a turbulent atmosphere over irregular terrain, Proc. IRE 43, 10 (1955)

[6] K. A. Norton, Point-to-point radio relaying via the scatter mode of tropospheric propagation, IRE Trans. CS-4, 1 (1956)

[7] R. E. Gray, The refractive index of the atmosphere as a factor in tropospheric propagation far beyond the horizon, IRE Natl. Conv. Record Pt. 1, 3 (1957).

[8] E. K. Smith and S. Weintraub, The constants in the equation for atmospheric refractive index at radio frequencies, Proc. IRE 41, 1035 (1953).

[9] B. R. Bean and J. D. Horn, Radio refractive-index climate near the ground, J. Research NBS 63D, (1959).

[10] W. A. Arvola, Refractive index profiles and associated synoptic patterns, Bull. Am. Meteorol. Soc. 38, 212 (1957).
[11] B. R. Bean and L. P. Riggs, On the synoptic variation of the radio refractive index, J. Research NBS 63D, (1959).

[12] C. L. Godske, T. Bergeron, and R. C. Bundgaard, Dynamic meteorology and weather forecasting, p. 526 (American Meteorological Society and Carnegie Institute of Washington, D.C., 1957).

[13] H. B. Byers, General meteorology, p. 327 (McGraw-Hill Book Co., Inc., New York, N.Y., 1944).

[14] F. A. Berry, E. Bollay, and Norman F. Beers, Handbook of meteorology, p. 638 (McGraw-Hill Book Co., Inc., New York, N.Y., 1945)

[15] J. B. Smyth and L. G. Trolese, Propagation of radio waves in the troposphere, Proc. IRE 35, 1198 (1947).

[16] B. R. Bean and G. D. Thayer, On models of the atmospheric radio refractive index, Proc. IRE 47, 740 (1959).

Boulder, Colo.

(Paper 63D2-21.) 